\title{
Systems of Meaning: Ethnography as a Methodology for the Study of Information Technologies
}

\author{
P. Prasad
}

Faculty of Management

University of Calgary

Calgary, Alberta, Canada

Tel: (403) 220-8803

E-mail: prasad@acs.ucalgary.ca

\begin{abstract}
This paper explores the implications of using ethnography as a methodology to study information technologies. It outlines the principal distinguishing characteristics of ethnographies by contrasting this methodology with other commonly used qualitative field research. It traces the philosophic roots of ethnography in symbolic anthropology and stresses the methodology's concern for thick description, plausibility of accounts, the cultural context and the immersion of the researcher. The paper also illustrates how the methodology can contribute to our understanding of Information Systems by discussing a few studies in this genre. It concludes by highlighting some recent dilemmas facing researchers in the ethnographic tradition.
\end{abstract}

\section{INTRODUCTION}

The recent qualitative turn in social science research has left unquestionable imprints on the discipline of information systems. The work of Markus (1983), Lee (1994), Orlikowski (1991; 1993), Kling and Iacono (1984), Walsham (1993) and others in this tradition is too well known to require elaboration here. While many qualitative researchers in the IS field concentrate on the analysis of electronic text and systems 
design (Lee 1994), others have resorted to indepth field studies of the implementation and adoption of information systems, relying primarily on the use of participant observation as a method of data collection (Orlikowski 1993; Ruhleder, Jordan and Elmes 1996). In the IS field, as in most others, the term ethnography has become the label of choice to designate qualitative fieldwork involving a sizeable amount of onsite observation.

The central contention of this paper is that the term ethnography holds distinct connotations for communities of scholars, thereby triggering specific expectations about its conduct and presentation which may not apply equally to all forms of qualitative fieldwork. As reviewers of qualitative work become more sophisticated, distinctions between ethnographic studies and other forms of qualitative fieldwork become more apparent and therefore more institutionally relevant (Wolcott 1995). A well-done piece of qualitative work can sometimes be faulted because of certain unwarranted claims to be ethnographic. It is therefore becoming increasingly necessary to understand the distinctions between different traditions of qualitative research and to grasp the specific connotations held by the term ethnography itself. Simultaneously, the practice of ethnography is increasingly being subjected to much debate and redefinition in disciplines such as anthropology and communication. The nature of assumptions undergirding ethnographies, the methodological expectations, and ethical stances adopted by researchers are all areas of growing intellectual contestation. For those of us who are users of this methodology, a renewed understanding of recent debates is likely to be of great relevance.

In this paper, a personal interpretation of the methodology of ethnography, focusing in particular on how it is distinctive rather than similar to other forms of qualitative fieldwork, is presented. While some might dispute the specific stance taken here, sharpening rather than broadening the concept of ethnography will ultimately offer us a more relevant methodology for understanding information systems. In sum, this paper attempts to do the following:

(a) broadly distinguish between ethnography and other forms of qualitative fieldwork,

(b) understand the complex set of anthropological traditions within which ethnography is rooted,

(c) present key features of ethnography as a methodology,

(d) discuss ethnographic applications to the study of information systems, and

(e) discuss contemporary dilemmas and debates confronting ethnographers.

\section{ETHNOGRAPHY AND QUALITATIVE FIELDWORK}

In most peoples' minds, the term ethnography denotes some form of in-depth fieldwork invariably employing participant observation, often used in combination with interviews or document analyses. From this perspective, ethnography is understood predominantly as a mode of data collection involving the development of close 
connections with subjects and situations being studied. While ethnographies would certainly imply all of these things, they also stand for something more. In this regard, it may be more useful to conceptualize ethnography as a methodology rather than a method which is linked to specific world views and approaches to understanding reality. The term methodology is used to designate the intricate set of ontological and epistemological commitments that a researcher brings to his/her work. Method, on the other hand, refers to the actual set of techniques and procedures used to collect and analyze data. Needless to say, one's choice of methodology eventually drives one's use of method. In this paper, the meaning and implications of using ethnography as a methodology for the study of information systems will be outlined.

Following the initial enthusiasm for qualitative research, several attempts have been made to sort out both the subtle and more obvious differences within diverse qualitative traditions (Hamilton 1993; Morgan and Smircich 1980). While these authors have alerted us to many fine distinctions between qualitative genres such as symbolic interaction, hermeneutics and structuralism, it may be useful to spend some time understanding one central distinction between different forms of qualitative fieldwork. This is the distinction between realist qualitative fieldwork and interpretive qualitative fieldwork, with ethnography (as a methodology) being clearly connected to the latter.

Briefly, we can think of realist traditions as holding relatively uncomplicated views of the world. At heart, realists believe that prolonged detached observation yields an accurate picture of reality. The underlying assumption behind realist fieldwork is that extended periods of observation accompanied by careful note-taking will result in an authentic assessment of the social situation under study. In essence, this view privileges the perspective and position of the researcher over that of the subjects being studied because it holds that ultimately the researcher's objective assessment of any social situation (given the right deployment of method) is a superior one.

Interpretive fieldwork (to which the methodology of ethnography is historically linked) is more concerned with understanding social situations from the standpoints of participants present within them. While interpretive fieldwork shares with realist fieldwork a strong predilection for extended observation and rich detail, it is always concerned with the process of cultural sense-making within any social situation. It is therefore, a mistake (although one made all too frequently) to think of ethnography solely in terms of depth of involvement (Wolcott 1995). Most qualitative traditions automatically imply a concern for depth of involvement. The crux of ethnography however, rests on the nature of that involvement which would emphasize a focus on local interpretations (Geertz 1973) and grasping the native point of view (Agar 1992; Schwartzman 1993). Anthropologists employ a somewhat useful terminology to underscore this distinction: that of etic versus emic research (Headland, Pike and Harris 1990).

At its most extreme, etic research implies that the researcher adopts a more exogenic approach to the field, avoiding close involvement with participants and trying to stay clear of presenting all but objective assessments of the situation. A classic study 
of IS change in the etic tradition is the longitudinal field study of an organization's adoption of electronic data processing equipment by Mann and Williams (1960). The authors spent months observing a technological change process, but commented on the event from a distant and detached perspective. Methodologically, ethnography clearly does not belong to the etic tradition. Coming from an emic or more endogenic perspective, it stresses what are often referred to as "native-view paradigms" (Gregory 1983) or reality as understood by the participants within it. Barley's (1988) study of CT scanners, for instance, is an appropriate example of an emic (ethnographic) study of technological change which takes into account the cultural sense-making and practices of organizational inhabitants in understanding a process of technical innovation.

It needs to be emphasized that the etic/emic distinction in the ethnographic tradition is no where as cut and dry as the preceding discussion might suggest. For example, as Van Maanen (1987) has pointed out, a number of realist field studies in the etic tradition claim to use ethnographic methods. First of all, it makes more sense to think of etic and emic research as lying on a continuum rather than being diametrically opposed to each other. Second, another way to sort out some of these ambiguities is to resort again to the distinction between method and methodology. Thus, many field studies that are obviously located within the etic tradition often use ethnographic methods, such as lengthy participant observation, and pay considerable attention to minute details. However, methodologically, these studies would still adhere primarily to etic objectives, depicting a more observer-based view of the situation being studied. Further, while the etic/emic distinction provides some clues to grasping the nature of ethnographic work, there is still much more to ethnography than its endogenic inclinations. To fully understand its complex characteristics, an appreciation of the anthropological tradition in which it is rooted is probably quite useful.

\section{THE ANTHROPOLOGICAL ROOTS OF ETHNOGRAPHY}

As a technique, ethnography has been developed, polished and perfected within the discipline of anthropology, from which it has since been exported to many social scientific fields including information systems research. While the discipline of sociology often lays claim to it, historically, as Schwartzman (1993, p. 1) points out, ethnography is the "trademark of cultural anthropology." It therefore makes sense to understand some of its historical intellectual antecedents. First of all, ethnography belongs to the subfield of anthropology originally known as cultural anthropology, and more recently referred to as symbolic anthropology. Unlike other fields within anthropology, notably structural-functionalism and evolutionist anthropology, symbolic anthropology tries to understand human action within cultural systems of meaning. Tracing its roots back to the work of Margaret Mead and Ruth Benedict, researchers within this field have traditionally used ethnography as a way of understanding "others" on their own terms. 
While symbolic anthropology's initial focus was on "primitive" cultures in distant lands, its approach has, in the latter half of the twentieth century, been extremely influential in shaping the study of a multitude of other issues of interest to contemporary social scientists including political processes (Bailey 1965), organizational interactions (Gregory 1983; Van Maanen and Kunda 1989) and patterns of modern consumption (Campbell 1987; Sherry 1990), to name only a few. In fact, it is possible to assert that hardly any aspect of contemporary life is now exempt from a cultural lens that relies on the methodology of ethnography.

This more recent absorption with cultural and symbolic approaches owes much to the work of Clifford Geertz, whose ideas will be briefly sketched out in the remainder of this section. Few scholars occupy as prominent a place in the field of symbolic anthropology as Geertz, whose main contribution lies in his attempt to theoretically mingle an understanding of human meaning and social action. To Geertz (1973), all human action is suspended in webs of significance which in turn are embedded in cultural codes and contexts. In other words, one can understand social situations only through appreciating the meanings they hold for people in a given culture. These meanings, in turn are always enacted through innumerable symbolic actions and artifacts such as ceremonies, rites, folklore, ritual, etc., which have an overall stable quality. Thus, for Geertz, one can only comprehend social processes through a cultural-symbolic lens that is engaged in searching for the local meanings or interpretations of relevant actors.

Geertz's evocative but somewhat over-used term for this kind of analysis is thick description, a phrase that has come to be employed almost synonymously with ethnography. While thick description is often used in more realist qualitative research to denote nothing more than rich detail, the term, in the Geertzian tradition, has far deeper connotations. In fact, Geertz's main concern was to alert ethnographers to the problems of analyzing social interactions without resorting to the local interpretations and cultural contexts of key participants. In his much celebrated essay on ethnography and thick description, Geertz (1973) highlights the difficulties confronting ethnographers who have to make sense of social events from the observation of simple actions. The illustration he uses is that of the wink. How, Geertz asks, can we discern from simple observation the difference between an eyelid twitch (involuntary physical movement) and a wink (voluntary conspiratorial act)? Further, the wink itself could have multiple connotative layers and could signify different things when engaged by different actors. After all, as Geertz pursues, an individual could be parodying a wink by an acquaintance, in which case his own wink becomes a burlesque rather than a conspiratorial act. Geertz's overall point is quite simple. Detailed observation of actions alone may not always provide a meaningful view of the situation. Rather, uncovering the multiple complex layers of local meanings or sorting out the structures of signification is what yields a comprehensive and insightful picture of any social circumstance being studied. Ethnography, therefore, in Geertz's (1973, p. 43) own words, is like "trying to read a manuscript - foreign, faded, full of ellipses, incoherencies, suspicious emendations and tendentious com- 
mentaries, but written not in conventionalized graphs of sound but in transient examples of shaped behavior."

Symbolic anthropology and the ethnographic method have had other recent influences as well, notably Mary Douglas, James Clifford and others. Since the scope of this paper does not permit a detailed discussion of their ideas, some of their contributions will be taken up when we discuss the more current dilemmas and debates confronting ethnographers in the social sciences.

\section{CENTRAL CHARACTERISTICS OF ETHNOGRAPHY}

Despite its dynamic and continuously changing nature, it is still possible to understand ethnography as constituting certain key elements. As Wolcott (1995), Frake (1983), and others assert, it is necessary to keep in mind that the methodology of ethnography refers simultaneously to a perspective, an approach, a set of procedures and a manner of presentation. More specifically, ethnographic research is not only about data collection and analysis, but also about writing and presenting one's findings. Some key (and mostly shared) elements that would characterize a study as being ethnographic are discussed below.

\subsection{The Use of Thick Description}

Ethnographers are firm believers in the use of thick description to uncover and analyze data. As discussed earlier, thick description (Geertz 1973) refers primarily to a researcher's development of understanding out of the sense-making and schemas of local participants. The key concept used in arriving at thick descriptions is that of meaning. When out in the field, ethnographers try to understand any situation based on the meanings that it holds for relevant social actors. These meanings may sometimes be shared; sometimes they may be contradictory and contested. It is the ethnographer's task to uncover and present these multiple meanings and their complex connections with each other in the course of analyzing any social event.

Too often, field workers are tempted to look only for shared meanings and agreements, or to present the views of more powerful and influential individuals and groups. Ethnography would insist on understanding multiple realities and uncovering the often complex sets of meanings associated with them. Thus, typically, in an ethnographic piece of writing, we can be faced with completely differing visions of reality based on different participants' interpretations of any situation. A good ethnographer will present these different interpretations and try to incorporate them into his/her analysis. It is in the skillful weaving of these contradictions and complexities that a thick description can be produced. 


\subsection{The Cultural Context}

Ethnographers are strongly wedded to understanding events and social interactions within a specific cultural context, whether it is a Sumatran island, a shopping mall or a professional law firm. The key focus here is on how specific cultures and subcultures shape both the interpretations and interactions of subjects being studied. The significance of cultural understanding to ethnography cannot possibly be over-emphasized. Given its anthropological genesis, ethnography seeks to locate actions within cultural circumstances. What this implies is a focus by researchers on cultural practices such as rituals, myths, taboos, etc., that guide everyday action in any situation.

While it is easy to view "foreign" and distant cultures as having these obvious cultural trappings, ethnographers would insist on understanding our own everyday lives in the same terms. Berg's (1985) study of technological change in a Volvo plant and Barley's study of a new CT scanner are exemplars of ethnographic approaches that are concerned with cultural processes. Berg's research explains the rise of what he terms as a "techno-culture" in a Swedish plant out of the traditional culture of craftsmanship that still pervaded the company. He argues that the strength of this new techno-culture could be best understood only by paying attention to some of the corporate myths that were compatible with this new subculture. Barley's work examines how the implementation of a new CT scanner was accomplished through many ritualistic processes that even led to the emergence of technological superstitions around the new system. In both studies, the authors' analyses of the technologies are distinctly influenced by cultural concepts such as myths, ritual, heroes, etc.

\subsection{Immersion and Connection}

Ethnography is almost synonymous with getting close to one's field. The careful development of close connections with one's subjects is a hallmark of ethnographic research (Agar 1980). In the anthropological tradition of the early twentieth century, field workers would spend extended periods of time in distant lands, where they frequently learned the language of the people they were studying. In our contemporary settings, familiarity with language remains as important as before. Ethnography implies not only understanding the jargon and terminology of the people one is studying, but also using this language in the writing of one's research to convey a flavor of the situation to readers. Golden-Biddle and Locke (1993) point out that ethnographies are often evaluated favorably when they convey a sense of authenticity to their readers. Accomplished ethnographers will insert phrases and comments made by their subjects to illustrate key points in their analysis. Van Maanen's (1973) wellknown study on the socialization of policemen is remarkable in part for the way in 
which the reader begins to appreciate the world of the rookie cop through the language used by many of the policemen.

Ethnography also implies a high level of familiarity with the field itself. Thus, the ethnographic tradition strongly favors the method of participant observation where researchers spend extended periods of time in the site, and sometimes even take on the roles of inhabitants within the site. Using an ethnographic approach calls for the cultivation of some degree of informal intimacy with the people being studied. Anthropologists often develop especially close relationships with one or two individuals, whom they refer to as informants, who clue the researcher into the more subtle and informal dynamics present in any social situation.

\subsection{The Plausibility of Accounts}

In describing the nature of ethnography, Golden-Biddle and Locke (1993), Rosen (1991), Wolcott (1995), Frake (1983), and others point out that producing an ethnography is as much about writing as it is about data collection and analysis. In other words, ethnographic research substantially involves a commitment to presenting one's findings in a way which is often described as providing a plausible account. Plausible accounts refer to ethnographic writings that are convincing not only because they pay attention to detail, but because the overall narrative incorporates the viewpoints of multiple actors and ties these together in a culturally coherent and articulate fashion. Thus, a great deal of effort necessarily goes into learning the form and style of ethnographic writing (Van Maanen 1987). Many features can contribute to the plausibility of the research narrative including the development of a strong story line, evidence of the researcher's own involvement in the field, a sense of historical context and a coherent weaving of disparate events within the field. Above all, an ethnography is ultimately judged also on its ability to offer convincing explanations of action in a particular culture or subculture, be it ancestral worship among the Yungur or obsessive relationships with computers among hackers at MIT. In doing this, ethnography is also primarily committed to insight over prediction. Ethnographers are more concerned with providing "authentic" explanations of human behavior and action than tightly forecasting specific events. While a powerful and plausible ethnographic account may well suggest that certain groups are likely to adopt certain patterns of action, that is not the main focus of ethnographic inquiry.

Creating a plausible account is also accomplished by inviting readers to see themselves in solidarity with the text's assertions (Golden-Biddle and Locke 1993). Skilled ethnographers make appeals to readers by connecting the topic or situation being researched to the everyday life worlds of readers themselves. In doing so, ethnographers establish insightful linkages between their own findings and parallel issues concerning readers. 


\subsection{Privileging Local Knowledge}

The purpose of ethnography is not the generation of universalistic knowledge in the form of what social scientists often refer to as grand theory. Many variants of traditional management theory and some forms of Marxist analysis would fall within this category of grand theory. In essence, grand theorists seek to understand human action through a set of universally applicable lenses. Typically, therefore, their understanding of specific events are mediated by broad intellectual categories such as race, status, class, and human nature. Ethnographers are almost unanimously opposed to any form of grand theorizing. Their epistemological position is one that squarely privileges local knowledge, and therefore sees theory building as being engaged in the development of what Geertz (1973) refers to as "particular truths" regarding a situation or phenomenon. For an ethnographer, grand theories conceal far more than they reveal because, in their zest for developing generalizable knowledge, they miss the local interpretations and cultural context that ultimately constitute such knowledge. Further, it is only through our understanding of microscopic interactions that any attempt to comprehend macro-structures is at all possible.

\section{ETHNOGRAPHY AND THE STUDY OF INFORMATION SYSTEMS}

The foregoing discussion has probably made quite obvious the fact that an ethnographic approach to understanding information systems cannot merely be equated with a qualitative stance. First of all, an ethnographic approach would regard information technologies as systems of meaning, i.e., as cultural artifacts holding multiple meanings for different people, and simultaneously being located within a broader cultural system of meaning. With the assistance of fieldwork done in the ethnographic tradition, we can better understand how to study information systems from this methodological standpoint. This section takes a close look at how some researchers of information systems have employed an ethnographic perspective. The field examples selected here illustrate rather vividly the contributions of an ethnographic methodology. The choice of studies discussed here in no way implies that other ethnographic studies have little to offer. While many other competent examples of ethnographic research can be found, the scope of this paper does not permit a detailed discussion of all of them.

The anthropological tradition within which ethnography is situated treats any technology as a cultural artifact accomplishing specific functions in different cultural milieus, and often reflecting and structuring social practices. Typically, ethnographers would adopt a more problematic understanding of technology, seeing it as having both functional and symbolic properties. In fact, the discipline of anthropology is filled with studies that illustrate the complex role of technologies in different 
societies. Most of these studies clearly demonstrate that technologies often fulfill far more than instrumental roles. They are often ceremonial (Berns 1990), reflect the myths of the culture that designs them (Harrison 1982) and can be used as mechanisms of social control (Berns 1990; Joerges 1989). When computer technologies are studied in this more ethnographic fashion, we are confronted with a more complex set of insights than studies that treat them merely as functional instruments designed to accomplish certain specific purposes.

Turkle's (1984) extraordinary ethnographic study of the intricate connections between computers and the human spirit falls within this genre. Turkle spent extensive periods observing and interviewing different populations in contemporary society including children, working men and women, hackers, etc., with a view to understanding the multiple subjective connotations held by the computer in today's society. Her project, in her own words, was to arrive at a portrait of the computer as an "evocative object" rather than solely a technical one. Turkle's study is not only richly detailed, but offers us, through an understanding of what the computer means to society, a better appreciation of the culture in which it is located. In her remarkable study, we see how computers take on various personifications in the minds of small children and adult hackers, and how they come to stand for democratic hopes in a society constantly searching for new alternatives to governance. In her complex analysis, Turkle never ignores the cultural context within which computers are located. Her discussion of the identification of personal computers with the personal politics of the 1960s helps explain some of their popularity in the late 1970s and 1980s. As she notes, "Personal computers became symbols of hope for a new populism in which citizens would band together to run information resources and local government" (Turkle 1984, p. 172).

In this study, we see how an ethnographic consciousness alerts readers to appreciating information technologies as symbolic and cultural objects that are also defined in part by the historic moments in which they are situated. Her discussion of the MIT hacker culture with its obsessive and intimate relationships to information technology reveals a masterful appreciation of cultural currents shaping these human-computer relationships. Her work constitutes good ethnography because of its analytic depth, its relentless search for cultural explanations, and its appreciation of computers as a fundamentally symbolic object. Other ethnographies of information technology in this genre are Pfaffenberger's (1989) study of personal computers and Prasad's $(1993 ; 1995)$ studies of the anthropomorphism of computers in a medical center. The latter study (Prasad 1995), in which approximately nineteen months were spent observing an organization's transition to computerization, documents the multiple ways in which the new technology was anthropomorphized by local organization members. In a careful recording of local terminology and language to demonstrate how the personification of computers was socially constructed, the researcher was trying to keep within the spirit of the ethnographic tradition, in part, because it pays so much attention to the computer system as a meaningful object. The study also tried to provide cultural explanations for this phenomenon and probed not only the local 
culture of the organization but also looked at comic books, TV shows, magazines and other vehicles of popular culture to enhance our understanding of how computers become personified in the workplace.

In these studies, the ethnographic approach results in an understanding of computer technology as cultural and symbolic object/artifact. This kind of analysis can easily be extended to different forms of information technologies such as groupware, expert systems, electronic communication and so on. The central focus of such inquiry would be on the multiple meanings evoked by these different systems and the implications such systems of meaning had for the use and misuse of these technologies.

In a slightly different oeuvre are the ethnographic studies of Barley (1988) and Zuboff (1988), both of whom were explicitly concerned with processes of change triggered by the introduction of new information systems. Barley's study was an indepth longitudinal ethnography of two organizations and their radiology departments in which a new CT scanner was introduced. Zuboff's study looked at the process and outcomes of computerization in eight different organizations including pulp mills, an insurance company, a telecommunications firm, a bank and a pharmaceutical company. Barley's work is a remarkable piece on alterations in the social organization of work following technological change. His work offers many insights, one noteworthy one being the ritualization whereby individuals in social situations become comfortable with new and often disquieting technologies. The ethnographic lens is used here not only to dictate methods of observation but also to root the analysis in cultural concepts such as ritual and magical thinking to understand technological processes.

Zuboff's work needs little introduction. Her extensive use of participant observation in eight different organizations, which she studied over a period of five years, stands out as an exemplar of ethnographic inquiry. Her insights regarding information technology's Janus-like capacity to both informate and automate work is consistently informed by the subjective experiences of different organizational participants as well as the historical-cultural context of white collar work and its symbolic status. Her work is ethnographic because she does not treat technological change as a onedimensional phenomenon, but locates it within other webs of significance such as authority relationships, the symbolic value of work, and the texture of oral versus electronic communication. Zuboff's work again offers guidelines for ethnographers of information systems by suggesting different cultural backdrops (e.g., organizational hierarchies, oral culture) against which their studies can be conducted.

\section{DILEMMAS/DEBATES FACING ETHNOGRAPHERS}

Despite (or perhaps because of) its growing popularity, ethnography has more recently been wrestling with several dilemmas regarding the role and responsibilities of the researcher, the conduct of the study and the presentation of the findings. While the debates are, for the most part, far too complex to be discussed in detail here, three major issues confronting ethnographers will be presented. They are the degree of 
researcher covertness, dilemmas of deep immersion, and the representation of subjects in the final writings of the researcher.

\subsection{The Overt/Covert Debate}

Anyone embarking on an ethnographic study needs to be aware of the debate around the ethics of using covert forms of observation. While many early anthropologists were too conspicuous within the sites they were studying to attempt any form of clandestine research, once ethnography was transferred to studying one's immediate social situation, the option of using covert methods became quite popular. One can find innumerable studies in which researchers took on certain roles such as meat packers (Thompson 1983), Pentecostal church members (Homan 1980), and even mental patients (Caudill 1952) without disclosing their identities to the people being studied.

Needless to say, this mantle of secrecy in ethnography has been subjected to much criticism in recent years. The obvious objection to this kind of clandestine observation is that the researcher might violate certain privacy considerations and be privy to some types of information that would have been unavailable if the ethnographic intentions had been openly disclosed. While it is quite easy to make certain personal decisions based on ethical considerations regarding the adoption of covert versus overt participation methods, ethnographers often find that the lines between openness and secrecy can become very blurred in actual field settings.

In my own study of computerization in a health maintenance organization (HMO), I began with the explicit and fully disclosed intention of studying how the process of computerization transformed the nature of work in the organization. After spending a few months in the organization, I began to feel that the symbolism associated with the change process was a far more interesting and worthy research project. When I attempted to communicate this changed focus to the HMO manager, I was received with blank stares and a response that my earlier focus was much more relevant to the organization itself. I eventually decided to effect a compromise by studying both angles, although I kept my interest on technological symbolism more to myself.

Several months after successfully defending my dissertation, I was engaged in a discussion on workplace resistance with several colleagues. One of them asked me if I had in fact found any resistance to the computerization process that I had been studying. The discussion led me to return to my field notes and interview transcripts, which I examined quite closely for instances of workplace resistance. Not only did I find several instances and discussions of resistance, I began writing about this issue with a greater passion than ever before. My point here is quite simple. When I started my work, my research intentions were completely different than when I finished. People in the organization were well aware that I was looking at changes associated with computerization. However, when I completed the study, I became more interested in an area which I had not disclosed to them for the simple reason that I had no intention at that time of studying resistance. Yet, it is entirely possible that 
had I disclosed such intentions, I might have been excluded from the site and made employees so self-conscious that I might not have found out much about resistance at all. Was my ethnography then, in fact, a covert project?

The answers to this question are obviously not that simple. Many ethnographers will frequently find themselves in similar situations in which their ostensible and original research focus becomes diverted into something quite different which they may or may not be able to disclose. Second, ethnographers periodically stumble on confidential material which may pose potential damage to certain individuals and groups. Here again, several ethical decisions may have to be made regarding the researcher's own responsibility to breach certain confidences. One thing is for sure: in embarking on ethnographic research, simplistic moral platitudes condemning all forms of covert research are certainly rendered more problematic.

\subsection{Dilemmas of Immersion}

Ethnography automatically implies some level of deep immersion in the culture one is studying. More recently, ethnographers have been seriously wrestling with what exactly is meant by the notion of immersion, and with what obligations this may leave us. As many ethnographers point out, becoming a part of the culture one studies may not always be either possible or desirable (Geertz 1973; Wax 1983). As Geertz argues, only romantics and spies want to become completely identified with another culture. For most ethnographers, the goal is more often one of learning enough about a site and its inhabitants so that we can present an authentic interpretation of their own experiences of their life worlds. However, even this level of comfortable familiarity is never easy to obtain. "Going native," to use a somewhat obsolete anthropological term, requires a genuine commitment to learning about others, as well as, on some occasions, a deliberate attempt to "perform" the role of the native. As Wax (1983: 197) suggests,

Perhaps good fieldwork is more like playacting than most of us are willing to admit. Respondents rarely resent a fieldworker's "acting like them" or "learning their ways" as long as a fieldworker makes it clear that he knows he is only playing a part and that his newly acquired skills do not entitle him to any privileges which they are not willing to offer him.

Yet, even developing this kind of understanding usually involves gaining the trust of one's subjects (Rosen 1991; Wax 1983). This ability to establish and maintain trust in a field setting while simultaneously being committed to authentically reporting on the same situation is always, at best, a precarious practice. Achieving some level of successful immersion means that people will confide in the researcher or reveal aspects of their personality and life which they would not share with most other people. Ethnographers who then write about these more intimate or confidential experiences in an indiscreet or instrumental fashion seriously rupture trusted relationships and leave very negative feelings in the communities that were being studied. 
One way of managing this process more delicately is to share one's proposed findings with some of one's subjects. While they might not always agree with the researcher's interpretation, they are likely to feel less exploited and to voice their disagreements with the researcher's findings. In many cases, this can further refine a researcher's narrative and turn it into an even more plausible account. The central issue here is that people resent having their experiences and relationships objectified in research articles, especially when the researcher has been regarded as a trustworthy member of their community. One way in which ethnographers can minimize this problem is by writing about people in a way that is more empathetic and human, rather than in the clinical language of the social sciences. Here again, anthropological narrative is a useful way in which ethnographers can talk about people in less commodified ways.

\subsection{Dilemmas of Representation}

The preceding discussion leads neatly into a more recent controversy around the way in which ethnographers represent individuals, groups and cultures in their writings. In the last decade or so, ethnography (along with other forms of academic writing) has been severely critiqued for the many cultural biases which pervade it. As Van Maanen (1995) asserts, ethnography is now on trial for its unreflective adherence to scientific principle, its hidden prejudices, and its frequent incapacity to incorporate marginal voices into its narrative form. In other words, ethnographers in anthropology, sociology, communication and other disciplines are engaged in seriously reexamining the tenets that guide their writings and influence their storytelling methods.

No longer is it sufficient to merely tell a good story (Rosaldo 1989; Van Maanen 1995). Ethnographers are now grappling with the kind of values that implicitly shape their own storytelling and reevaluating the agendas that undergird their own research. In particular, anthropologists are exploring how ethnographies can speak more respectfully of less privileged groups (e.g., third world cultures) and bring in the voices of marginal groups (e.g., women, the poor). This debate is also forcing ethnographers to come to terms with their own privilege vis a vis some of their more powerless subjects and to recognize that the ethnographic project itself is embedded in a web of power relations (Behar 1993).

While these concerns might seem esoteric to researchers of information systems, a little reflection would suggest that is not really the case. In our own work, we are constantly representing both powerful groups (e.g., systems designers and senior management) and less powerful ones (e.g., clerical workers and data entry operators). How we represent these diverse groups, their concerns, and their arguments is what the issue of representation is all about. For instance, students of systems design are often unwittingly disrespectful of those who resist technological change. Many studies will either dismiss such resistance as an outcome of pathological or ignorant beliefs (Nord and Jermier 1994) or treat it solely as a problem to be overcome. Those who resist new information systems are often regarded as old fashioned, wary of 
progress, or ignorant and are implicitly represented as less knowledgeable and therefore to be taken less seriously. The current debates on representation alert ethnographers of technological change against taking such stances. At the very least, they also clue us into thinking about how we can meaningfully talk about people whose opinions are tacitly considered less knowledgeable.

Some questions they force upon us are

- How should we speak about resistance and resistors?

- Why are we so quick to treat resistance so pejoratively?

- How do we make space in our research for the voices of resistors to be heard?

While the answers to these questions are obviously not simple, they force us to wrestle with these and other problematic issues.

\section{SOME CONCLUDING THOUGHTS}

Today, few would oppose the use of qualitative methodologies for the study of information systems. In a post-positivist world, where multiple qualitative approaches such as ethnomethodology, ethnography, hermeneutics, and deconstruction are clamoring for our attention, we need to be increasingly clear about the implications of specific methodological choices. In this paper, an attempt was made to clarify some key implications in employing ethnography as a methodology for the study of information systems. In doing so, the intent was to dispel some of the confusion surrounding the term and to show how the methodology of ethnography was different rather than similar to many other popular genres of qualitative fieldwork. Such a stance is useful because researchers using the term become more cognizant of its implication and they will have a better sense of the ethnographic tradition, which primarily implies a constant engagement with the notion of culture. Too often, aspiring ethnographers, while paying attention to detail and immersion, ignore the cultural context which is at the heart of the ethnographic project. What this paper has tried to stress is that the lens of culture provides an analytic standpoint that is distinct from other qualitative traditions such as realist case methodology, semiotics, and phenomenology.

Further, it is probably evident by now that a major strength of ethngoraphy lies in its ability to lend itself easily to disciplinary hybridity, or what Geertz (1980) has termed the "blurring of the genres" whereby insights from literary theory, history and other disciplines can be woven into ethnographies of information systems. However, as the paper has also stressed, ethnography, while immensely attractive and insightful, is not an easy methodology to practice. While most people are familiar with the rigor it demands in terms of data collection, few pay sufficient attention to the theoretical orientation it demands or the complex issues it raises in the process of writing and researching. Yet, to anyone who has engaged in an ethnographic project, the insights it offers are often sufficient compensation for the emotional and intellectual demands 
it imposes. Certainly in a field such as MIS, still lacking a substantial ethnographic voice, its contribution would make its rigorous practice a worthwhile effort.

\section{REFERENCES}

Agar, M. H. (1980). The Professional Stranger: An Informal Introduction to Ethnography. New York: Academic Press.

Agar, M. H. (1992). Speaking of Ethnography. Newbury Park, California: Sage Publications.

Bailey, F. G. (1965). Stratagems and Spoils: A Social Anthropology of Politics. Oxford: Basil Blackwell.

Barley, S. R. (1988). "The Social Construction of a Machine: Ritual, Superstition, Magical Thinking and Other Pragmatic Responses to Running a CT Scanner." In M. Lock and D. Gordon (Editors), Knowledge and Practice in Medicine: Social, Cultural and Historical Approaches. Boston: Kluwer Academic Publishers, pp. 497-540.

Behar, R. (1993). Translated Woman: Crossing the Border with Esperanza's Story. Boston: Beacon Press.

Berg, P. O. (1985). "Techno-Culture: The Symbolic Framing of Technology in a Volvo Plant." Scandanavian Journal of Management Studies, Volume 4, pp. 237 256.

Berns, M. C. (1990). "Pots as People: Yungur Ancestral Portraits." African Arts, Volume 23, 23: 50-60.

Campbell, C. (1987). The Romantic Ethic and the Spirit of Modern Consumerism. London: Basil Blackwell.

Caudill, W. C. (1952). "Social Structure and Interaction Processes in a Psychiatric Ward." American Journal of Orthopsychiatry, Volume 22, pp. 314-334.

Clifford, J., and Marcus, G. E. (1986). Writing Culture: The Poetics and Politics of Ethnography. Berkeley: University of California Press.

Frake, C. O. (1983). "Ethnography." In R. M. Emerson (Editor), Contemporary Field Research. Boston: Little Brown, pp. 60-67.

Geertz, C. (1973). The Interpretation of Cultures. New York: Basic Books.

Geertz, C. (1980). "Blurred Genres: The Refiguration of Social Thought." The American Scholar, Volume 49, p. 165-179.

Golden-Biddle, K., and Locke, K. (1993). “Appealing Work: An Investigation of How Ethnographic Texts Convince." Organization Science, Volume 4, pp. 595616.

Gregory, K. L. (1983). “'Native View' Paradigms: Multiple Cultures and Culture Conflicts in Organizations." Administrative Science Quarterly, Volume 28, pp. 359-376.

Hamilton, D. (1993). “Traditions, Preferences and Postures in Applied Qualitative Research." In N. Denzin and Y. Lincoln (Editors), Handbook of Qualitative Research. Thousand Oaks, California: Sage Publications, pp. 60-69. 
Harrison, S. (1982). "Yams and the Symbolic Representation of Time in a Sepik River Village." Oceania, Volume 53, pp. 141-162.

Headland, T. N.; Pike, K. L.; and Harris, M. (1990). Emics and Etics: The Insider/Outsider Debate. Newbury Park, California: Sage Publications.

Homan, R. (1980). "The Ethics of Covert Methods." British Journal of Sociology, Volume 31, pp. 46-59.

Joerges, B. (1989). "Romancing the Machine: Reflections on the Social Scientific Construction of Computer Reality." International Studies of Management and Organization, Volume 19, pp. 24-50.

Kling, R., and Iacono, S. (1984). "Computing as an Occasion for Social Control." Journal of Social Issues, Volume 40, pp. 77-36.

Lee, A. S. (1994). "Electronic Mail as a Medium for Rich Communication: An Empirical Investigation Using Hermeneutic Interpretation." MIS Quarterly, Volume 18, pp. 143-157.

Mann, F. C., and Williams, L. K. (1960). "Observations on the Dynamic Nature of a Change to Electronic Data Processing Equipment." Administrative Science Quarterly, Volume 5, pp. 217-256.

Markus, M. L. (1983). "Power, Politics and MIS Implementation." Communications of the ACM, Volume 26, pp. 430-444.

Morgan, G., and Smircich, L. (1980). "The Case for Qualitative Research." Academy of Management Review, Volume 5, pp. 491-500.

Nord, W., and Jermier, J. (1994). "Overcoming Resistance to Resistance: Insights from a Study of Shadows." Public Administration Quarterly, Volume 17, pp. 396409.

Orlikowski, W. (1991). "Integrated Information Environment or Matrix of Control? The Contradictory Implications of Information Technology." Accounting, Management and Information Technologies, Volume 1, pp. 9-42.

Orlikowski, W. (1993). "CASE Tools as Organizational Change: Investigating Incremental and Radical Changes in Systems Development." MIS Quarterly, Volume 17, pp. 309-339.

Pfaffenberger, B. (1989). "The Social Meaning of the Personal Computer or Why the Personal Computer Revolution Was no Revolution." Anthropological Quarterly, Volume 61, pp. 39-47.

Prasad, P. (1993). "Symbolic Processes in the Implementation of Technological Change: A Symbolic Interactionist Study of Work Computerization." Academy of Management Journal, Volume 36, pp. 1400-1429.

Prasad, P. (1995). "Working with the 'Smart' Machine: Computerization and the Discourse of Anthropomorphism in Organizations." Studies in Cultures, Organizations and Societies, Volume 1, pp. 253-265.

Rosaldo, R. (1989). Culture and Truth. Boston: Beacon Press.

Rosen, M. (1991). "Coming to Terms with the Field: Understanding and Doing Organizational Ethnography." Journal of Management Studies, Volume 28, pp. $1-24$. 
Ruhleder, K.; Jordan, B.; and Elmes, M. B. (1996). "Wiring the 'New Organization'." Proceedings of the Annual Meetings of the Academy of Management, Cincinnati, August.

Schwartzman, H. (1993). Ethnography in Organizations. Newbury Park, California: Sage Publications.

Sherry, J. F. (1990). "A Sociocultural Analysis of a Midwestern Flea Market." Journal of Consumer Research, Volume 17, pp. 13-30.

Thompson, W. E. (1983). "Hanging Tongues: A Sociological Encounter with the Assembly Line." Qualitative Sociology, Volume 6, pp. 215-237.

Turkle, S. (1984). The Second Self: Computers and the Human Spirit. New York: Simon and Schuster.

Van Maanen, J. (1973). "Observations on the Making of Policemen." Human Organization, Volume 32, pp. 407-418.

Van Maanen, J. (1987). Tales of the Field: On Writing Ethnography. Chicago: University of Chicago Press.

Van Maanen, J. (1995). "An End to Innocence: The Ethnography of Ethnography." In J. Van Maanen (Editor), Representation in Ethnography. Thousand Oaks, California: Sage Publications, pp. 1-35.

Van Maanen, J., and Kunda, G. (1989). “'Real Feelings': Emotional Expression and Organizational Culture." Research in Organizational Behavior, Volume 11, pp. 43-103.

Walsham, G. (1993). Interpreting Information Systems in Organizations. New York: Wiley.

Wax, R. H. (1983). "The Ambiguities of Fieldwork." In R. E. Emerson (Editor), Contemporary Field Research. Boston: Little Brown, pp. 191-202.

Wolcott, H. F. (1995). "Making a Study more Ethnographic." In J. Van Maanen (Editor), Representation in Ethnography. Thousand Oaks, California: Sage Publications, pp. 79-111.

Zuboff, S. (1988). In the Age of the Smart Machine: The Future of Work and Power. New York: Basic Books.

\section{BIOGRAPHY}

Pushkala Prasad is an associate professor at the University of Calgary where she teaches organization theory, qualitative methodology and management skills. Her research interests are in the areas of technological symbolism, resistance to computerization, workplace diversity and philosophies of research methods. Her work has been published in a number of journals including Academy of Management Journal and Journal of Management Studies and Organization Science. She has just coedited a book entitled Managing the Organizational Melting Pot: Dilemmas of Workplace Diversity. She recently was named an Ascendent Scholar by the Western Academy of Management. Professor Prasad has been a visiting professor at the Helsinki School of Economics and at Lund University in Sweden. 